\title{
Out-of-pocket healthcare expenditure in Australia: trends, inequalities and the impact on household living standards in a high-income country with a universal health care system
}

\author{
Emily J. Callander ${ }^{1 *}$ (D, Haylee Fox ${ }^{1}$ and Daniel Lindsay ${ }^{2}$
}

\begin{abstract}
Background: Poor health increases the likelihood of experiencing poverty by reducing a person's ability to work and imparting costs associated with receiving medical treatment. Universal health care is a means of protecting against the impoverishing impact of high healthcare costs. This study aims to document the recent trends in the amount paid by Australian households out-of-pocket for healthcare, identify any inequalities in the distribution of this expenditure, and to describe the impact that healthcare costs have on household living standards in a highincome country with a long established universal health care system. We undertook this analysis using a longitudinal, nationally representative dataset - the Household Income and Labour Dynamics in Australia Survey, using data collected annually from 2006 to 2014. Out of pocket payments covered those paid to health practitioners, for medication and in private health insurance premiums; catastrophic expenditure was defined as spending 10\% or more of household income on healthcare.
\end{abstract}

Results: Average total household expenditure on healthcare items remained relatively stable between 2006 and 2014 after adjusting for inflation, changing from $\$ 3133$ to $\$ 3199$. However, after adjusting for age, self-reported health status, and year, those in the lowest income group (decile one) had 15 times the odds ( $95 \% \mathrm{Cl}, 11.7-20.8)$ of having catastrophic health expenditure compared to those in the highest income group (decile ten). The percentage of people in income decile 2 and 3 who had catastrophic health expenditure also increased from 13\% to 19\% and 7\% to 13\% respectively.

Conclusions: Ongoing monitoring of out of pocket healthcare expenditure is an essential part of assessing health system performance, even in countries with universal health care.

Keywords: Out-of-pocket expenditure, Universal health care, Australia, Inequality, Household living standards, Poverty

\section{Introduction}

Poor health increases the likelihood of experiencing poverty by reducing a person's ability to work and imparting costs associated with receiving medical treatment. Those who develop a chronic disease have a higher chance of leaving the workforce [29], and as such see a decline in their income as they lose the wages associated with paid

\footnotetext{
* Correspondence: e.callander@griffith.edu.au

${ }^{1}$ School of Medicine, Griffith University - Gold Coast campus, G05 Room

2.24, Southport, Queensland 4125, Australia

Full list of author information is available at the end of the article
}

employment [25]. This chain of events has been observed internationally $[1,24,28]$ - as health, being a key form of human capital, universally effects a person's ability to participate in employment [3]. Countries with a welfare system may provide an income safety net for those who are too ill to work, thus providing a [small] supplementary income stream in the form of transfer payments. None-the-less, multiple studies have shown that those who develop a chronic disease face an increased risk of falling into income poverty, even in

(c) The Author(s). 2019 Open Access This article is distributed under the terms of the Creative Commons Attribution 4.0 International License (http://creativecommons.org/licenses/by/4.0/), which permits unrestricted use, distribution, and 
High-Income Countries (HICs) with such welfare systems in place $[4,5,7]$.

Poor health and the negative impact it can have on living standards is important for a number of reasons. Governments with welfare systems to support those who are too ill to work will see an increase in the number of transfer payments being made; the more people out of the labour force due to ill health reduces the revenue base from which governments can draw an income stream to finance these transfer payments; and from the individual perspective, declining income reduces the amount of disposable income available to finance access to healthcare. This illustrates the cross-portfolio issues associated with the health-living standards nexus; highlighting the far-reaching impacts that poor health can have on both the Government and individual's financial capacity.

Poor health not only adversely affects people's financial capacity due to withdrawal from the labour force; poor health can also affect financial capacity by increasing the amount of household expenditure on healthcare related items. Healthcare is more of a 'necessary' good, as opposed to a 'discretionary' good [17], with people often having little choice as to whether they access it or not. As such, increasing expenditure on healthcare has a similar effect to decreasing income: it reduces the amount of disposable income available to families to spend on other goods, such as food, education, transport and entertainment.

Universal health care means that all people have access to the health services they need without being exposed to financial hardship when doing so [8]. Poorer people within the population have the greatest need for health care as they are more likely to suffer from illness and disease [2]. Therefore, contributions should be based on ability to pay and health services should be allocated according to need, ensuring that high out-of-pocket healthcare costs are mitigated, and the associated impoverishing potential of poor health is reduced [8]. Australia has a universal health care system, Medicare, which was introduced in 1984. In response to the spiralling costs facing the Australian state to financing this system, ongoing health care reform has led to an interrogation of the amount being paid out-of-pocket by individuals [26]. Previous research in this area has looked at out-of-pocket expenditure at a single point in time $[6,35]$, or focused upon expenditure by a single sub-population [21, 32]. However, it has been noted that the basis of the Medicare system - to provide universal health care is being undermined by increasing out-of-pocket costs [20].

Against this background, this study has three research questions:
1. What do Australians currently pay for household healthcare expenditure and how has this changed over time?

2. What proportion of individuals live in households that have 'catastrophic healthcare expenditure', and what is the distribution of catastrophic expenditure by income group?

3. How many additional people would be in income poverty when household income is adjusted for household healthcare expenditure?

The overall aim of this paper is to document the recent trends in the amount paid by Australians out of pocket for healthcare, identify any inequalities in the distribution of this expenditure, and to describe the impact that household healthcare costs have on living standards in a HIC with a long established UHC system. While internationally, much attention has been given to identifying catastrophic healthcare expenditure [30, 31, 34], to date this has been a relatively overlooked area within Australia. The studies that have been conducted to date have only looked at older Australians with chronic health conditions [21] or specific chronic health conditions [16], and none have looked at the population as a whole.

\section{Methods}

\section{Australia's healthcare system}

Australia's publically financed national universal health insurance scheme, Medicare, was introduced to promote equity by improving access and affordability of health services. Through Medicare, patients are able to access treatment in public hospitals free of charge, and receive subsidised out of hospital treatment. Patients are provided a rebate benefit for services that are utilised for out of hospital treatment. The rebate amount is based upon a proportion of a schedule of fees covering each type of service. For example, for a consultation with a General Practitioner lasting 20 min or more, the schedule fee in 2017 is $\$ 71.70$, and the benefit is $100 \%$ of the schedule fee, or \$71.70; a blood test associated with diabetes management has a schedule fee of $\$ 16.80$ and the benefit is $75 \%$ of the schedule fee, or $\$ 12.80$ [12]. While public hospitals are managed by the state, most out of hospital services are delivered by private providers. The actual amount charged by providers for services is set by the providers themselves, and these charges are not regulated, meaning that providers are able to set their fees above the schedule fee. Any difference between the price providers charge for a service and the rebate amount is paid by patients 'out-of-pocket'. For illustration, if a provider charged $\$ 25.00$ for a blood test associated with diabetes management, Medicare would provide a rebate of $\$ 12.80$ ( $75 \%$ of the schedule fee), leaving the patient to 
pay $\$ 12.20$. Medicare has policies designed to help protect patients from high out of pocket costs. Health Care Cards are provided to welfare recipients and low income earners, and entitles holders to pay a lower out of pocket fee for prescription medicines [13]. The 'Medicare Safety Net' and 'Extended Medicare Safety Net' Programs also provide higher rebates if an individual or family group reaches a certain amount of total expenditure on out of pocket fees within a calendar year. Any subsequent services or prescriptions will have a higher proportion subsidized for the rest of that calendar year [15]. Under the "Medicare Safety Net", once the threshold is reached $100 \%$ of the schedule fee for all services is rebated; and under the "Extended Medicare Safety Net" 80\% of the actual out-of-pocket fees are rebated. For Health Care Card holders the threshold of total expenditure that needs to be reached to receive the "Extended Medicare Safety Net" is lower [14].

\section{Dataset to be used for this study - HILDA}

Microdata from waves 6 to 14 of the Household Income and Labour Dynamics in Australia (HILDA) Survey was utilised for this study. The HILDA survey is a longitudinal survey of private Australian households conducted annually since 2001 , with release 14 , containing data from waves 1 (2001) to wave 14 (conducted in 2014), the latest to be released at the time of writing this paper. The data are nationally representative of the Australian population living in private dwellings and aged 15 years and over. There were 6547 records of individuals aged 20 years and over in Wave 6 of the continuing sample HILDA survey, representing $10,381,000$ people in the Australian population.

The survey sampling unit for Wave 1 from which the continuing sample is drawn was the household, with all members of the household being part of the sample that would be followed for the life of the survey. Household sampling was conducted in a three-stage approach. Initially, 488 Census Collection Districts (each containing 200 to 250 households) were selected. Within each district, 22 to 34 dwellings were then selected, and finally, up to three households within each dwelling were selected to be part of the sample [27]. The data is weighted to be representative of the Australian population and to account for any bias introduced through respondent attrition. The initial household cross-sectional weights in Wave 1 (upon which the weights in subsequent waves are dependent) were derived from the probability of selecting the household and were calibrated so that the weighted estimates match known benchmarks for the number of adults by the number of children and state by part of the state. The person-level weights were based on the household weights and then calibrated so that person weights match known benchmarks for sex by age, state by part of the state, state by labour force status, marital status and household composition. The longitudinal weights adjusted for attrition and were benchmarked against the characteristics of Wave 1. For a detailed description of HILDA weighting see Watson (2012). All dollar values in this study were adjusted to 2014 Australian dollars based upon Consumer Price Inflation (CPI) (2017) [23].

\section{Household healthcare expenditure}

Wave 6 onwards in the HILDA survey asked respondents to estimate the amount the household spent annually on fees paid to:

- Health practitioners;

- Medicines, prescriptions, pharmaceuticals, alternative medicines; and.

- Private health insurance.

The reported amounts were recorded separately for each of the three categories. For the purpose of this study, the three groups were summed to create a total health care expenditure amount. All results are reported at the individual level, but for household expenditure.

\section{Household income}

For this study, the total regular household income minus taxes was utilised. For the assessment of the distribution of healthcare expenditure, this measure of household income was equivalised using the OECD-modified (De [11]) equivalence scale. This accounted for the number of adults (aged 15 and over), and the number of children (aged 14 and under) living in the household.

\section{Catastrophic healthcare expenditure}

Within Australia, there is no accepted threshold for what proportion of a household's income makes expenditure on healthcare 'catastrophic'. Therefore, will be using a threshold of $10 \%$, based upon a previous study conducted within Australia, although other cut-offs have been used internationally [31]. Individuals who have $10 \%$ or more of their total regular household income minus taxes that are taken up by household healthcare expenditure are deemed to have 'catastrophic' healthcare expenditure [22].

\section{Impoverishing healthcare expenditure}

Impoverishing healthcare expenditure is an expenditure that places a household's income below the poverty line. The $50 \%$ of the median equivalised income poverty line was utilised, which is the accepted cut-off for poverty measurement in Australia [9] and differs from the 60\% used in other countries [18]. The total amount of household expenditure on healthcare was subtracted from total regular household income minus taxes. This was 
then equivalised, again, using the OECD-modified (De [11]) equivalence scale.

\section{Statistical analysis}

The initial descriptive analysis was undertaken to quantify the average out of pocket household expenditure on healthcare for each year between 2006 and 2014.

The proportion of people with catastrophic healthcare expenditure in each income decile was then identified. A generalised estimating equation model was then constructed to assess the odds of having catastrophic health care expenditure for those in different income decile. The model was adjusted for age, sex, self-assessed health status and year, with those in income decile ten used as the reference group.

A concentration index was constructed for each year between 2006 and 2014 to identify the cumulative proportion of people with catastrophic healthcare expenditure by cumulative proportion of the population, ranked by equivalised household income The concentration index (CI), and it's associated 95\% confidence intervals, were computed as follows:

$$
2 \sigma_{R}^{2}\left(\frac{y_{i}}{\mu}\right)=\alpha+\beta R_{i}+\varepsilon_{i}
$$

Where $R_{i}$ is the rank of each individual, $\sigma_{R}^{2}$ is the variance of $R_{i}, y_{i}$ is the catastrophic healthcare status of each individual $(\mathrm{i}=1,2,3 \ldots \mathrm{N}), \alpha$ is the intercept, $\varepsilon_{i}$ is the error terms, and $\beta$ is the CI [19].

\section{Results}

Table 1 shows the average amount of household expenditure on healthcare practitioners; medicines, pharmaceuticals, and alternative medicines; and private health insurance. Average total household expenditure on healthcare items has only slightly increased after adjusting for inflation between 2006 and 2014 from $\$ 3133$ to $\$ 3199$ (in 2014 dollars). This appears to be mostly driven by increases in private health insurance expenditure, which was on average $\$ 1242$ in 2006 and increased steadily to $\$ 1557$ in 2014. Average expenditure on healthcare practitioners decreased slightly between 2006 and 2014 from $\$ 1188$ in 2006 to $\$ 1099$ in 2014, and expenditure on medicines, pharmaceuticals, and alternative medicines remained somewhat constant.

Table 2 shows that the proportion of people with catastrophic healthcare expenditure decreases with income decile - with those in the lowest income decile having the highest percentage of people with catastrophic healthcare expenditure. The concentration index for the distribution of catastrophic expenditure was - 0.39 (95\% CI: $-0.43,-0.34)$ in 2006 , and increased to -0.46 (95\% CI: $-0.50,-0.42)$, showing an increase in the distribution
Table 1 Mean total household out of pocket expenditure on healthcare costs; healthcare practitioners; medicines, pharmaceuticals, alternative medicines; and private health insurance, 2006-2014

\begin{tabular}{llll}
\hline Year & $\mathrm{n}$ & Mean & Std Error of Mean \\
\hline Total healthcare expenditure & & \\
2006 & 6265 & 3133 & 90 \\
2007 & 6265 & 3065 & 50 \\
2008 & 6324 & 3158 & 55 \\
2009 & 6362 & 3073 & 52 \\
2010 & 6390 & 3192 & 75 \\
2011 & 6409 & 3162 & 61 \\
2012 & 6421 & 3129 & 48 \\
2013 & 6429 & 3198 & 53 \\
2014 & 6429 & 3199 & 51
\end{tabular}

Expenditure on healthcare professionals

$\begin{array}{lll}2006 & 6265 & 1188\end{array}$

$\begin{array}{llll}2007 & 6265 & 1195 & 29\end{array}$

$\begin{array}{llll}2008 & 6324 & 1221 & 30\end{array}$

$\begin{array}{llll}2009 & 6362 & 1152 & 32\end{array}$

$\begin{array}{llll}2010 & 6390 & 1213 & 35\end{array}$

$\begin{array}{llll}2011 & 6409 & 1241 & 46\end{array}$

$\begin{array}{llll}2012 & 6421 & 1113 & 28\end{array}$

$\begin{array}{llll}2013 & 6429 & 1122 & 31\end{array}$

$\begin{array}{llll}2014 & 6429 & 1099 & 30\end{array}$

Expenditure on medicine, pharmaceuticals and alternate medicine

$\begin{array}{llll}2006 & 6265 & 703 & 77 \\ 2007 & 6265 & 607 & 20 \\ 2008 & 6324 & 590 & 18 \\ 2009 & 6362 & 589 & 14 \\ 2010 & 6390 & 560 & 10 \\ 2011 & 6409 & 563 & 11 \\ 2012 & 6421 & 570 & 12 \\ 2013 & 6429 & 575 & 14 \\ 2014 & 6429 & 544 & 12\end{array}$

Expenditure on private health insurance

$\begin{array}{llll}2006 & 6265 & 1242 & 22\end{array}$

$2007 \quad 6265 \quad 1263 \quad 23$

$\begin{array}{llll}2008 & 6324 & 1348 & 29\end{array}$

$\begin{array}{llll}2009 & 6362 & 1331 & 26\end{array}$

$\begin{array}{llll}2010 & 6390 & 1418 & 59\end{array}$

$\begin{array}{llll}2011 & 6409 & 1358 & 24\end{array}$

$\begin{array}{llll}2012 & 6421 & 1447 & 25\end{array}$

$\begin{array}{llll}2013 & 6429 & 1500 & 27\end{array}$

$\begin{array}{llll}2014 & 6429 & 1557 & 28\end{array}$


Table 2 Proportion of households with catastrophic healthcare expenditure by decile, 2006-2014

\begin{tabular}{|c|c|c|c|c|c|c|c|c|c|}
\hline Income quintile & 2006 & 2007 & 2008 & 2009 & 2010 & 2011 & 2012 & 2013 & 2014 \\
\hline 1 & $31 \%$ & $24 \%$ & $25 \%$ & $35 \%$ & $25 \%$ & $32 \%$ & $33 \%$ & $35 \%$ & $31 \%$ \\
\hline 2 & $13 \%$ & $17 \%$ & $16 \%$ & $20 \%$ & $17 \%$ & $21 \%$ & $18 \%$ & $19 \%$ & $19 \%$ \\
\hline 3 & $7 \%$ & $10 \%$ & $15 \%$ & $11 \%$ & $17 \%$ & $12 \%$ & $16 \%$ & $12 \%$ & $13 \%$ \\
\hline 4 & $6 \%$ & $9 \%$ & $9 \%$ & $6 \%$ & $9 \%$ & $10 \%$ & $10 \%$ & $7 \%$ & $10 \%$ \\
\hline 5 & $8 \%$ & $7 \%$ & $8 \%$ & $7 \%$ & $9 \%$ & $9 \%$ & $9 \%$ & $11 \%$ & $9 \%$ \\
\hline 6 & $4 \%$ & $5 \%$ & $5 \%$ & $3 \%$ & $4 \%$ & $5 \%$ & $5 \%$ & $3 \%$ & $5 \%$ \\
\hline 7 & $4 \%$ & $4 \%$ & $6 \%$ & $4 \%$ & $4 \%$ & $3 \%$ & $5 \%$ & $6 \%$ & $5 \%$ \\
\hline 8 & $4 \%$ & $3 \%$ & $3 \%$ & $3 \%$ & $4 \%$ & $2 \%$ & $3 \%$ & $4 \%$ & $2 \%$ \\
\hline 9 & $3 \%$ & $3 \%$ & $4 \%$ & $3 \%$ & $2 \%$ & $3 \%$ & $3 \%$ & $2 \%$ & $2 \%$ \\
\hline 10 & $1 \%$ & $2 \%$ & $2 \%$ & $1 \%$ & $1 \%$ & $2 \%$ & $0 \%$ & $3 \%$ & $3 \%$ \\
\hline $\begin{array}{l}\text { Concentration } \\
\text { Index }\end{array}$ & $\begin{array}{l}-0.39(-0.43, \\
-0.34)\end{array}$ & $\begin{array}{l}-0.40(-0.45 \\
-0.36)\end{array}$ & $\begin{array}{l}-0.43(-0.48, \\
-0.39)\end{array}$ & $\begin{array}{l}-0.39(-0.43 \\
-0.34)\end{array}$ & $\begin{array}{l}-0.44(-0.49, \\
-0.40)\end{array}$ & $\begin{array}{l}-0.48(-0.52, \\
-0.43)\end{array}$ & $\begin{array}{l}-0.53(-0.58 \\
-0.48)\end{array}$ & $\begin{array}{l}-0.46(-0.50 \\
-0.41)\end{array}$ & $\begin{array}{l}-0.46(-0.50 \\
-0.42)\end{array}$ \\
\hline
\end{tabular}

of catastrophic healthcare expenditure towards those of lower income over time.

Relative to those in the highest income decile, there was an increasing likelihood of having catastrophic healthcare expenditure with decreasing income decile. After adjusting for age, self-reported health status, and year, those in income decile one had 15.63 times the odds (95\% CI: 10.88-22.43) of having catastrophic health expenditure compared to those in income decile ten (Table 3).

Finally, we estimated the number of people who would have been classified as being in income poverty, had income been adjusted for the amount of healthcare expenditure. In 2006, an additional 141,000 people were in income poverty. In 2014, an additional 285,000 people were in income poverty (Table 4).

\section{Discussion}

Average household out-of-pocket expenditure on healthcare - covering expenditure on health practitioners, medication and private health insurance premiums - has remained relatively constant after adjusting for inflation between 2006 and 2014 for the general adult population in Australia. However, those with lower incomes were more likely to have catastrophic healthcare expenditures (spending 10\% of more of household income on healthcare) over this time period, and between 2006 and 2014 there was increasing inequality in the distribution of catastrophic healthcare expenditure towards those with lower income. The impact of household healthcare expenditure on household living standards was such that after adjusting household income for healthcare expenditure in excess of 200,000 additional people would be classified as being in income poverty within Australia in 2014.

No previous study has sought to assess the distribution of the impact of out-of-pocket expenditure, nor sought to assess the impoverishing consequences of healthcare expenditure in Australia. Co-payments and the impact they have had on accessing primary health care services in Australia was discussed by Laba et al. [20], and a previous study has shown that 1 in 4 Australians with a chronic health condition skip care due to the cost [6]. This highlights the importance of assessing the level of out-of-pocket expenditure on healthcare and identifying population groups who may be disproportionately affected.

The use of self-reported healthcare expenditure is a key weakness of this study, which is also common to all previous studies that used individual-level data to assess of out-of-pocket health care expenditure in Australia. It could be questioned whether individuals are able to accurately recall the amount they have spent on healthcare, which may have influenced the accuracy of the results. However, the amount of expenditure reported in this study was similar to the amount reported in a previous study on healthcare expenditure [35]. Future research may be able to make better use of health administrative data to overcome these issues or use short recall periods [10].

Financial risk protection is a core objective of universal health coverage [33]. Although Australia has a universal health care system, this study has demonstrated that Australia's health system may not be protecting its most vulnerable citizens against catastrophic health expenditure and income poverty, which disproportionally burdens the most disadvantaged people within the population. If a health care system is to meet the objectives of universal health coverage, total contributions should be based on ability to pay, and health care services should be allocated according to need, which means poorer people should receive greater health care benefits due to greater health care needs [33]. Through 
Table 3 Generalised Estimating Equation model of likelihood of having catastrophic healthcare expenditure

\begin{tabular}{|c|c|c|c|c|}
\hline \multirow{2}{*}{$\frac{\text { Parameter }}{\text { Age (years) }}$} & \multirow{2}{*}{$\frac{\text { Odds Ratio }}{1.04}$} & \multicolumn{2}{|c|}{ 95\% Confidence Limits } & \multirow{2}{*}{$\frac{p \text {-value }}{<.0001}$} \\
\hline & & 1.04 & 1.04 & \\
\hline Income decile 1 & 15.63 & 10.88 & 22.43 & $<.0001$ \\
\hline Income decile 2 & 7.43 & 5.74 & 9.61 & $<.0001$ \\
\hline Income decile 3 & 6.12 & 4.90 & 7.65 & $<.0001$ \\
\hline Income decile 4 & 4.43 & 3.71 & 5.28 & $<.0001$ \\
\hline Income decile 5 & 4.81 & 3.98 & 5.82 & $<.0001$ \\
\hline Income decile 6 & 2.38 & 2.18 & 2.59 & $<.0001$ \\
\hline Income decile 7 & 2.58 & 2.33 & 2.85 & $<.0001$ \\
\hline Income decile 8 & 1.79 & 1.71 & 1.87 & 0.0001 \\
\hline Income decile 9 & 1.67 & 1.62 & 1.72 & 0.0013 \\
\hline Income decile 10 & REFERENCE & & & \\
\hline Very poor self assessed health & 1.24 & 1.23 & 1.26 & 0.1221 \\
\hline Poor self assessed health & 1.35 & 1.34 & 1.37 & 0.0064 \\
\hline Fair self assessed health & 1.25 & 1.25 & 1.26 & 0.0319 \\
\hline Good self assessed health & 1.02 & 1.00 & 1.04 & 0.8705 \\
\hline Excellent self assessed health & REFERENCE & & & \\
\hline 2006 & 0.75 & 0.73 & 0.78 & $<.0001$ \\
\hline 2007 & 0.80 & 0.78 & 0.83 & 0.0062 \\
\hline 2008 & 0.91 & 0.89 & 0.93 & 0.2041 \\
\hline 2009 & 0.88 & 0.87 & 0.90 & 0.051 \\
\hline 2010 & 0.88 & 0.87 & 0.89 & 0.0299 \\
\hline 2011 & 0.96 & 0.95 & 0.97 & 0.4938 \\
\hline 2012 & 1.01 & 1.00 & 1.01 & 0.8708 \\
\hline 2013 & 1.00 & 1.00 & 1.00 & 0.9945 \\
\hline 2014 & REFERENCE & & & \\
\hline
\end{tabular}

the Extended Medicare Safety Net Scheme the Australian government seeks to do this. However this study indicates that Australia's universal health system appears to not safeguard the poorest people in society, which are the people who need it the most, against the financial hardship associated with accessing health care. Universal health systems should develop in a way that does not impose harm to other social sectors in people's lives by imposing catastrophic health expenditures upon households.

Table 4 Additional number of people who would be in income poverty when household income is adjusted for household healthcare expenditure

\begin{tabular}{llll}
\hline Year & $\begin{array}{l}\text { Actual number of people } \\
\text { in income poverty }\end{array}$ & $\begin{array}{l}\text { Number of people in income poverty, } \\
\text { adjusted for healthcare costs }\end{array}$ & $\begin{array}{l}\text { Additional number } \\
\text { of people in poverty }\end{array}$ \\
\hline 2006 & $1,187,000$ & $1,328,000$ & 141,000 \\
2007 & $1,392,000$ & $1,545,000$ & 153,000 \\
2008 & $1,371,000$ & $1,524,000$ & 153,000 \\
2009 & $1,388,000$ & $1,549,000$ & 161,000 \\
2010 & $1,424,000$ & $1,639,000$ & 215,000 \\
2011 & $1,410,000$ & $1,617,000$ & 207,000 \\
2012 & $1,436,000$ & $1,658,000$ & 222,000 \\
2013 & $1,408,000$ & $1,607,000$ & 199,000 \\
2014 & $1,302,000$ & $1,587,000$ & 285,000 \\
\hline
\end{tabular}




\section{Conclusions}

Out-of-pocket payments are considered to be the most regressive form of financing a health system [33]. These results highlight the financial impact experienced by households as a consequence of this regressive approach to providing health care to the population. The findings clearly demonstrate the importance of vigilance to ensure ongoing progress towards universal health coverage, rather than assuming that financial risk protection is an inevitable outcome of having a universal health system.

\begin{abstract}
Abbreviations
HIC: High Income Country: defined by the World Bank as a country with a gross national income per capita US\$12,056 or more in 2017. HILDA: Household Income and Labour Dynamics in Australia: a longitudinal survey of private Australian households; OECD: Oganisation for Economic Cooperation Development: is an intergovernmental economic organisation with 36 member countries, founded in 1961 to stimulate economic progress and world trade; UHC: Universal Health Care: is a health care system that provides health care and financial protection to all citizens of a particular country
\end{abstract}

\section{Acknowledgements}

None

\section{Funding}

EC received salary support from a National Health and Medical Research Council (NHMRC) Career Development Fellowship (APP1159536).

\section{Availability of data and materials}

The HILDA data utilised in this study is available upon request from the University of Melbourne.

\section{Authors' contributions}

EC conceived the study design and led the overall study. HF drafted the manuscript. DL undertook the analysis. All authors contributed to the interpretation of the results and editing of the final manuscript. All authors read and approved the final manuscript.

\section{Competing interests}

Associate Professor Callander receives part of her salary from a National Health and Medical Research Council (NHMRC) Career Development Fellowship. All authors declare that they have no conflicts of interest that are directly or indirectly related to the research.

\section{Publisher's Note}

Springer Nature remains neutral with regard to jurisdictional claims in published maps and institutional affiliations.

\section{Author details}

${ }^{1}$ School of Medicine, Griffith University - Gold Coast campus, G05 Room 2.24, Southport, Queensland 4125, Australia. ${ }^{2}$ College of Public Health, Medical and Veterinary Science, James Cook University, Townsville, QLD 4810, Australia.

Received: 12 September 2018 Accepted: 1 March 2019

Published online: 11 March 2019

\section{References}

1. Alavinia SM, Burdorf A. Unemployment and retirement and ill-health: a cross-sectional analysis across European countries. Int Arch Occup Environ Health. 2008:82(1):39-45.

2. Australian Institute of Health and Welfare (AlHW) (2016). Australia's health 2014. In: Understanding health and illness. Canberra: ACT, Australian Government; 2016

3. Becker GS. Health as human capital: synthesis and extensions. Oxf Econ Pap. 2007:59:379-410.
4. Callander E, Schofield D. Arthritis and the risk of falling into poverty: a survival analysis using Australian data. Arthritis Rheumatol. 2015a;68(1):255-62.

5. Callander $\mathrm{E}$, Schofield $\mathrm{D}$. Type 2 diabetes mellitus and the risk of falling into poverty: an observational study. Diabetes Metab Res Rev. 2016;32(6):581-8.

6. Callander EJ, Corscadden L, Levesque J-F. Out-of-pocket healthcare expenditure and chronic disease - do Australians forgo care because of the cost? Aust J Prim Health. 2017;23(1):15-22.

7. Callander EJ, Schofield DJ. Psychological distress and the increased risk of falling into poverty: a longitudinal study of Australian adults. Soc Psychiatry Psychiatr Epidemiol. 2015b;50(10):1547-56.

8. Chan M, Brundtland G. Universal health coverage: an affordable goal for all. Geneva: World Health Organisation; 2016.

9. Community Affairs Reference Committee. A hand up not a hand out: Renewing the fight against poverty. Senate Inquiry into Poverty 2004. Canberra: The Senate; 2004.

10. Dalziel K, Li J, Scott A, Clarke P. Accuracy of patient recall for self-reported doctor visits: is shorter recall better? Health Econ. 2018;27(11):1684*1698.

11. De Vos K, Zaidi MA. Equivalence scale sensitivity of poverty statistics for the member states of the European community. Rev Income Wealth. 1997:43(3): 319-33.

12. Department of Health. Medicare Benefits Schedule Book: Operating from 01 September 2017. Canberra: Australian Government; 2017.

13. Department of Human Services. (2019a). "Medicare safety net 2019 table of thresholds." Retrieved 18 January, 2019, from https://www.humanservices. gov.au/individuals/services/medicare/medicare-safety-net/thresholds/2019table-thresholds

14. Department of Human Services. (2019b). "What the benefits are of a health care card." Retrieved 18 January, 2019, from https://www.humanservices. gov.au/individuals/enablers/what-benefits-are-health-care-card/39581.

15. Duckett S, Willcox S. The Australian health care system. Victoria: Australia, Oxford University Press; 2015.

16. Essue B, Kelly P, Roberts M, Leeder S, Jan S. We can't afford my chronic illness!The out-of-pocket burden associated with managing chronic obstructive pulmonary disease in western Sydney. J Health Serv R Policy. 2011;16:226-31.

17. Farag M, NandaKumar A, Wallack S, Hodgkin D, Gaumer G, Erbil C. The income elasticity of health care spending in developing and developed countries. Int J Health Care Finance Econ. 2012;12(2):145-62.

18. Gordon D. Poverty and social exclusion in Britain. Bristol: The Policy Press; 2006.

19. Kakwani N, Wagstaff A, Van Doorslaer E. Socioeconomic inequalities in health: measurement, computation, and statistical inference. J Econ. 1997; 77(1):87-103.

20. Laba T-L, Usherwood T, Leeder S, Yusuf F, Gillespie J, Perkovic V, Wilson A Jan S, Essue B. Co-payments for health care: what is their real cost? Aust Health Rev. 2015;39(1):33-6.

21. McRae I, Yen L, Jeon Y-H, Herath PM, Essue B. Multimorbidity is associated with higher out-of-pocket spending: a study of older Australians with multiple chronic conditions. Aust J Prim Health. 2013:19(2):144-9.

22. McRae I, Yen L, Jeon Y, Herath M, Essue B. The health of senior Australians and the out-of-pocket healthcare costs they face. Canberra. In: National Seniors Australia; 2012

23. Reserve Bank of Australia. (2017). "Measures of consumer Price inflation." Retrieved 1 January, 2017.

24. Schofield D, Shrestha R, Passey M, Earnest A, Fletcher S. Chronic disease and labour force participation among older Australians. Med J Aust. 2008;189: 447-50.

25. Schofield D, Shrestha R, Percival R, Passey M, Kelly S, Callander E. Economic impacts of illness in older workers: quantifying the impact of illness on income, tax revenue and government spending. BMC Public Health. 2011; 11(418).

26. Senate Standing Committees on Community Affairs. Out-of-pocket costs in Australian healthcare. Canberra: Commonwealth of Australia; 2014.

27. Summerfield M, Freidin S, Hahn M, Ittak P, Li N, Macalalad N, et al. HILDA User Manual - Release 12. Melbourne: The University of Melbourne; 2013.

28. van den Berg T, Schuring M, Avendano M, Mackenbach J, Burdorf A. The impact of ill health on exit from paid employment in Europe among older workers. Occup Environ Med. 2010;67(12):845-52

29. van Rijn RM, Robroek SJ, Brouwer S, Burdorf A. Influence of poor health on exit from paid employment: a systematic review. Occup Environ Med. 2014; 71(4):295-301. 
30. Wagstaff A, Doorslaer E v. Catastrophe and impoverishment in paying for health care: with applications to Vietnam 1993-1998. Health Econ. 2003; 12(11):921-33.

31. Wagstaff A, Flores G, Hsu J, Smitz M-F, Chepynoga K, Buisman LR, van Wilgenburg K, Eozenou P. Progress on catastrophic health spending in 133 countries: a retrospective observational study. Lancet Glob Health. 2018;6(2): e169-79.

32. Wong CY, Greene J, Dolja-Gore X, Gool K. The rise and fall in out-of-pocket costs in Australia: an analysis of the strengthening Medicare reforms. Health Econ. 2017;26(8):962-79.

33. World Health Organisation. World health report, 2010: health systems financing the path to universal coverage. In: World health report, 2010: health systems financing the path to universal coverage; 2010.

34. Xu K, Evans DB, Kawabata K, Zeramdini R, Klavus J, Murray CJ. Household catastrophic health expenditure: a multicountry analysis. Lancet. 2003; 362(9378):111-7.

35. Yusuf F, Leeder S. Can't escape it: the out-of-pocket cost of health care in Australia. MJA. 2013;199(7):475-8.

Ready to submit your research? Choose BMC and benefit from:

- fast, convenient online submission

- thorough peer review by experienced researchers in your field

- rapid publication on acceptance

- support for research data, including large and complex data types

- gold Open Access which fosters wider collaboration and increased citations

- maximum visibility for your research: over $100 \mathrm{M}$ website views per year

At BMC, research is always in progress.

Learn more biomedcentral.com/submissions 